\title{
The impacts of day trading activity on market quality: evidence from the policy change on the Taiwan stock market
}

Tun-Ya Yang

National Sun Yat-sen University, Kaohsiung, Taiwan

Si-Yuan Huang

National Dong Hwa University, Hualien, Taiwan, and

Wei-Che Tsai and Pei-Shih Weng

National Sun Yat-sen University, Kaohsiung, Taiwan

\begin{abstract}
This paper aims to investigate the impact of day trading on market quality on the Taiwan stock market with the implementation of a unique policy change. This paper examines 396 listed stocks from June 2015 to October 2016, a period when the stock market in Taiwan officially approved selected stocks for day trading for all investors. Within the sample period, the empirical findings show that day trading increases the bid-ask spread, price depth and stock volatility, indicating that day trading activities not only cause higher transaction costs and trading risk but also raise the market's ability to absorb price impact. This paper considers two-stage regression and tests the exogenous shock because of further relaxation for day trading to deal with the possible endogenous problem and the main findings remain consistent. Since early 2014, the Taiwan stock market has been experiencing a distinct growth in trading volume after unwinding the day trading; however, the results show that the impacts of stock day trading on market quality are not all positive.
\end{abstract}

Keywords Day trading, Bid-ask spread, Price depth, Volatility

Paper type Research paper

\section{Introduction}

Day trading is a high-frequency trading strategy wherein traders enter and exit the market within one day to earn quick and small profit and avoid the risk of overnight price change. Considerable discussions about the impact of day trading on the financial market are available in the existing literature. By frequently moving in and out of the market, day traders are expected to provide considerable liquidity to the market similarly to noise traders (Black, 1986; Malkiel, 1999; Chou et al., 2015). Bloomfield et al. (2009) create a laboratory market and find that noise trading increases market volume and depth but

(C) Tun-Ya Yang, Si-Yuan Huang, Wei-Che Tsai and Pei-Shih Weng. Published in Journal of Derivatives and Quantitative Studies: 선물연구. Published by Emerald Publishing Limited. This article is published under the Creative Commons Attribution (CC BY 4.0) licence. Anyone may reproduce, distribute, translate and create derivative works of this article (for both commercial and non-commercial purposes), subject to full attribution to the original publication and authors. The full terms of this licence maybe seen at http://creativecommons.org/licences/by/4.0/legalcode

JEL classification - G12, G14, G18

Received 21 June 2020 Revised 24 August 2020 Accepted 24 August 2020 
JDQS 28,4

192

reduces bid-ask spreads and the temporary price impact of trades. Chou et al. (2015) present that day traders exhibit consistent characteristics with those of Bloomfield et al.'s (2009) experimental results. Meanwhile, Barber and Odean (2001) argue that day traders may provide market liquidity by moving in and out extremely quickly, but they tend to profit from short-term momentum cycles to increase the stock volatility potentially. How does day trading affect the market? The prior literature on day trading still has considerable debates.

The Taiwan Stock Exchange (TWSE) is one of the major stock exchanges in Asia and has been founded for more than 50 years [1]. The TWSE, however, only started to allow day trading in 2014, whereas many leading stock exchanges in Asian countries, for example, Korea and Japan, removed the day trading restrictions in the 1990s. By exploiting this policy change with a daily disclosure of the day trading volume for each stock on the TWSE - the information, which is less available in other markets - our study aims to examine the impact of day trading on market quality.

Statistics show that many markets allowing day trading can benefit from increasing the trading volume, which is primarily contributed by individual traders. For example, day trading helps explain why Japanese individuals now account for more than $40 \%$ of the nation's equity volume or about as much as the overseas institutions that once were the most prominent traders [2]. Similarly, after permitting investors to engage in day trading of securities on the spot market from 2014, the TWSE produced a remarkable success that increased market trading dollar volume from 23tn to 29tn, which represents a $26 \%$ growth, by the end of 2014 . Figures 1 and 2 also show the share volume of day trading and the percentage day trading on the TWSE. As reported, the volume growth has a distinct uptrend from 2014 [3].

Given that day trading increases trading volume and attracts more retail traders, our research question remains unsolved: to the aspect of market quality, is day trading beneficial or harmful to the market? To answer this question, our study investigates the impact of day trading from three dimensions of market quality, namely, bid-ask spread, price depth and stock volatility.

In previous studies, two main challenges existed in testing the impact of day trading on the stock market. First, the available day trading data in the stock market are relatively scant. As a result, most prior literature adopts an indirect way to measure day trading and across a shorter sample period. For example, Koski et al. (2008) use message board activity to measure day trading strategy on National Association of Securities Dealers Automated Quotations (NASDAQ) stock for two quarters. Some studies use NASDAQ small order execution system to measure day trading (Battalio et al., 1997; Harris and Schultz, 1998). The

Figure 1.

The volume of day trading after January 1,2014

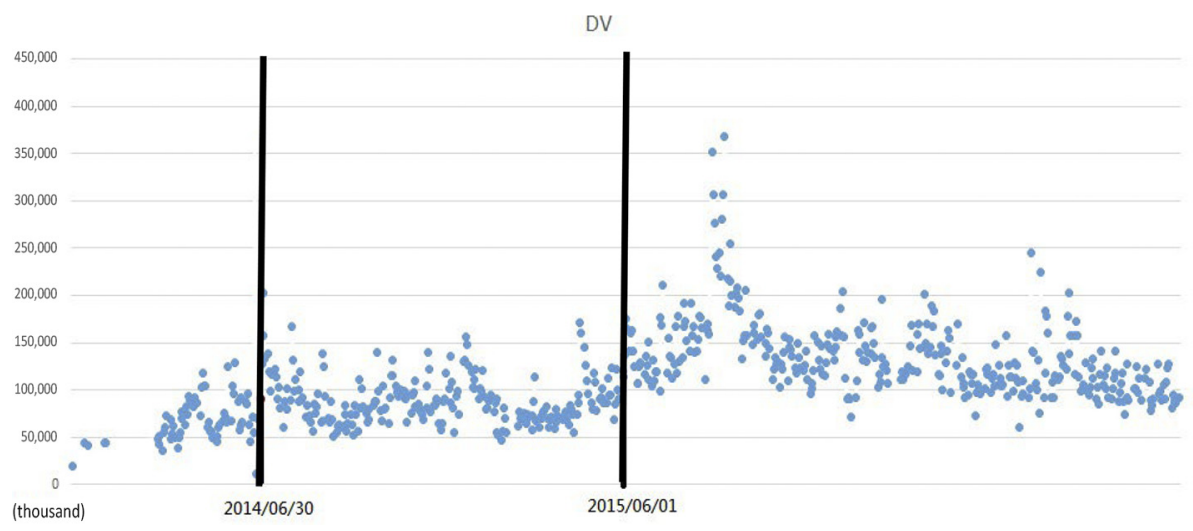


DVP

25

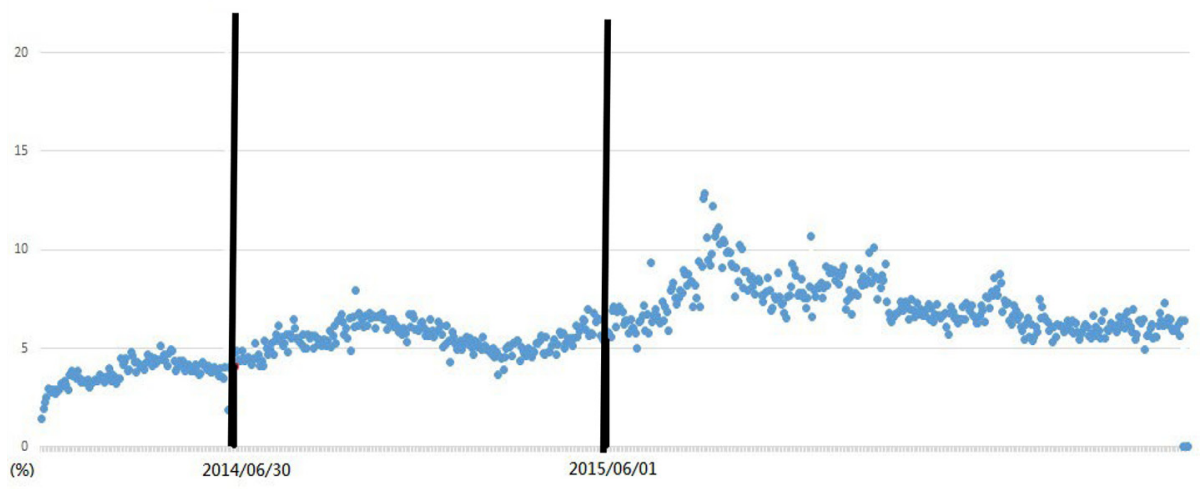

Day trading activity

193

Figure 2.

The percentage of day trading after January 1,2014

daily report of the day trading volume on the TWSE has an advantage; hence, our study adopts the amounts and percentages of day trading for each stock to measure the day trading activities directly.

Second, the trading qualities of a stock market, such as bid-ask spread and volatility, are not affected by day trading exogenously; however, these qualities may influence the incentives of day traders. In other words, the relationship between day trading and market quality may not be single directional but subject to the endogenous problem that prior literature rarely noticed. Fortunately, a policy change on the TWSE enables us to use an exogenous shock for day trading to observe its native impact on the market. Starting June 1, 2015, apart from the stocks that comprise the Taiwan 50, Taiwan Mid-Cap 100 and TPEx50 indices, day trading for underlying stocks of equity warrants will be permitted. This change allows us to observe the influence of day trading on market quality variables directly for newly eligible stocks and compare it with the impact on originally eligible companies. Besides, we perform two-stage regression to deal with the exogenous problem.

To measure market quality, we follow the approach used by Corwin and Schultz (2012) in estimating bid-ask spread and volatility and adopt the illiquidity ratio of Amihud (2002) in measuring price depth. These proxies need the daily variables only for the estimation, which is, therefore, advantageous when intraday variables are less available. Amihud's ratio has been widely used in the literature. Corwin and Schultz (2012) also show that their proxies are as valid as other proxies estimated by intraday variables.

Currently, there are two arguments in the existing literature regarding the influence of day trading activity. One stream of research proposes that day traders provide market liquidity without significantly exacerbating price volatility. For example, Chou et al. (2015) examine day traders on the Taiwan futures market and find that individual day traders provide market liquidity but have no influence on exacerbating stock volatility. Similarly, Hsieh et al. (2020) examine day trading on the TWSE and find that the market liquidity increases when the market releases the restriction on the "buying first and selling later" day trading.

The other stream of research criticizes that day trading could destroy market efficiency as day trade exacerbates stock volatility. For example, Kyrolainen (2008) examines the trading record of Finnish day traders and finds a strong positive time-series relation 
JDQS 28,4

between the number of day trades by individual investors and intraday volatility among heavily day-traded stock. Meanwhile, Chung et al. (2009) examine day trading activities on the Korea Stock Exchange and find that more frequent day trading activity leads to higher return volatility and that past day trading negatively affects bid-ask spreads.

This study's empirical findings show that day trading, no matter in volume or percentage, significantly increases bid-ask spread and volatility, but decreases illiquidity ratio. A wider bid-ask spread indicates higher transaction cost, whereas higher volatility indicates greater trading risk. Overall, these results imply that day trading increases the trading risk and cost for investors on the TWSE, a deterioration for the market quality. However, the illiquidity ratio is decreased by day trading, which indicates greater price depth [4]. Combined with these findings, the impact of day trading on liquidity varies in different aspects, as does the market quality.

The research of Hsieh et al. (2020) is closely related to our study, but this paper is different from the prior research in two respects. First, our study examines the market quality by multiple aspects, including market liquidity and volatility, while Hsieh et al. (2020) only focus on market liquidity. Second, Hsieh et al. (2020) examine the impact of day trading on the market liquidity across different policy implementation stages and make the comparison while our study attempts to clarify the overall effect of day trading activities on the market quality. Accordingly, we select our sample period from June 2015, as the TWSE has allowed the two-way day trading and further increased the number of stocks eligible for day trading to nearly 400. By contrast, Hsieh et al's (2020) sample period is from 2013 and ended by 2015 , which covers only the initial stages of policy implementation on relatively fewer permitted stocks.

To address the concern of endogeneity, we use two-stage regression to reexamine and find similar results. Moreover, we consider the policy of "further relaxation for more day trading stocks" in 2015 as the exogenous shock for day trading in testing its impact on market quality [5]. The findings show that the day trading volume and all market quality variables only have little change in the stocks that have been permitted in the day trading before further relaxation. By contrast, those stocks in the newly incorporated day trading significantly have more trading volume, greater volatility, wider bid-ask spread and higher price depth. In sum, these findings suggest that the endogenous problem, if any, would not affect our prior results.

Overall, our empirical findings show that the introduction of day trading on the TWSE boosts trading activities in the market; the quality of market trading, however, does not necessarily be improved. As an implication for the trading practice, we suggest that market regulators should not view the effect of boosting the market growth as the only one concern when launching a new trading policy but must consider the compounding influence of the policy implementation. Besides, retail traders should be more aware of the negative impacts of day trading. Although day trading minimizes the delivery costs for stock transactions and could be more attractive for retail traders who are generally cash-strapped, retail traders are also unavoidably more vulnerable to the higher trading risk caused by day trading.

The rest of this paper is organized as follows. Section 2 describes the sample and methodology. Section 3 presents our empirical findings. Section 4 concludes this paper.

\section{Data and methodology}

\subsection{Data}

We collect trading data, including daily high price, daily low price, daily closing price, daily turnover, daily trading volume (day trading and aggregated trading), stock market index, firm size and the leverage ratio from Taiwan Economic Journal, a leading financial database 
company in Taiwan, and the TWSE website. Our final sample consists of 396 listed companies on the TWSE from June 1, 2015, to October 31, 2016. Although day trading has been permitted since 2014 on the TWSE, only components stocks of the Taiwan 50 Index, Taiwan Mid-Cap 100 Index and TPEx50 Index are eligible for securities day trading. From June 2015, besides the 200 initially selected companies, the underlying stocks of warrants traded on the Taiwan stock market are also available for day trading. To enlarge our sample size, we, therefore, collect sample companies from June 2015.

On the TWSE, the regular trading hours are from 09:00 to 13:30. Investors may engage in day trading by buying first and selling later or selling first and buying later, securities of the same type and quantity during regular trading hours. They may also engage in day trading by buying during regular trading hours and then selling in after-hours fixed-price trading or by selling during regular trading hours and then buying in after-hours fixed-price trading. Our estimation on market quality variables is based on the daily information in regular trading hours; hence, we only consider the trades in the same period for the volume of day trading.

\subsection{Variables}

To examine the market quality, we adopt liquidity and volatility in the analysis. We measure market liquidity by bid-ask spread and price depth. Although many studies estimate bid-ask spread using intraday observation, Corwin and Schultz (2012) developed a new approach to calculate bid-ask spread by using daily data and proved that it is as effective as other intraday spread measures. Following Corwin and Schultz (2012), we use regular trading variables to estimate bid-ask spread (S). The details of the estimation are introduced in Appendix 1. We also evaluate market liquidity using Amihud's (2002) illiquidity ratio, ILLQ, which is defined as the average daily ratio of absolute stock return to its dollar volume. The smaller the $I L L Q$, the higher is the price depth, indicating greater market liquidity.

Finally, we consider the impact of day trading on stock volatility. Obtaining a precise measure of stock volatility for a specific day is difficult because the commonly used measure, standard deviation, must be estimated by several observations within a period. Again, we follow Corwin and Schultz's (2012) approach to measure volatility (Sigma) because it can calculate the volatility for a specific day and only need a pair of trading data for two consecutive days. Alternately, the variation between the highest and lowest price within a day $(H L)$ is proposed to measure the volatility in the analysis.

In this study, the independent variable is day trading. The TWSE regularly discloses the daily volume of day trading for each permitted stock. We consider two alternate definitions for day trading: the share volume of day trading $(D V)$ and the percentage of day trading $(D V P) . D V P$ is calculated as the percentage ratio of total trading volume for a permitted stock.

In addition to the dependent and independent variables, we adopt a set of control variables, including trading variables and basic firm characteristics. The control variables are turnover rate, individual stock returns, the debt ratio of the firm, firm size and the level of the stock market index. Turnover is the daily turnover rate for a stock. To capture the asymmetric effect of returns, we decompose stock returns into a positive component (Retp) and negative component (Retn). Debt ratio $(D R)$ is the ratio of total debt over the total asset. Firm size (Size) is the logarithmic market value of a stock. We also adopt the Formosa Stock Index (the logarithmic price index) to measure the level of the Taiwan stock market (MI). Although the TWSE index is the primary stock index in Taiwan, our sample includes some stocks that are not component companies of the TWSE index but listed on the Taipei
Day trading activity

$-2$


JDQS 28,4

Exchange (TPEx), which is another local stock exchange operated for smaller companies. Formosa Stock Index converts all existing TWSE and TPEx stocks into one new benchmark index and aims to measure the overall level for the Taiwan stock market.

\subsection{Methodology}

To verify whether all variables in this study are suitable for the regression, we conduct the correlation analysis first prior to the regression analysis. The results will be presented in the latter section. Moreover, we perform panel regression and control for the daily and monthly effects. The regression models are as follows:

Model 1:

$$
\begin{aligned}
\text { LIQ }_{t, i}= & \alpha+\beta_{1} X_{t, i}+\beta_{2} \text { Turnover }_{t, i}+\beta_{3} \operatorname{Retp}_{t, i}+\beta_{4} \operatorname{Retn}_{t, i}+\beta_{5} D R_{i}+\beta_{6} \text { Size }_{i} \\
& +\beta_{7} M I_{t}+\varepsilon_{t}
\end{aligned}
$$

$L I Q_{t, i}$ is the stock liquidity that is measured by bid-ask spread $\left(S_{t, i}\right)$ and illiquidity $\left(I L L Q_{t, i}\right)$. $X_{t, i}$ is the day trading volume (DV) or the percentage of day trading $(D V P)$ and Turnover $_{t, i}$ is the turnover rate. $\operatorname{Ret}_{t, i}$ and $\operatorname{Retn}_{t, i}$ are positive and negative returns, respectively. All aforementioned variables are measured for stock $i$ at day t. Moreover, $D R_{t}$ and Size $_{t}$ are the debt ratio and logarithm market value for stock $i$, respectively. Finally, $M I_{t}$ is the stock market index at day t.

Model 2:

$$
\begin{aligned}
\text { Vol }_{t, i}= & \alpha+\beta_{1} X_{t, i}+\beta_{2} \text { Turnover }_{t, i}+\beta_{3} \operatorname{Retp}_{t, i}+\beta_{4} \operatorname{Retn}_{t, i}+\beta_{5} D R_{i}+\beta_{6} \text { Size }_{i} \\
& +\beta_{7} M I_{t}+\varepsilon_{t}
\end{aligned}
$$

$\operatorname{Vol}_{t, i}$ is the stock volatility that is measured by Sigma $a_{t, i}$ or the variation between the highest and the lowest price within a trading day $\left(H L_{t, i}\right)$ for stock $i$ at day t. The control variables are defined as Model 1.

\section{Empirical results and analysis}

\subsection{Descriptive statistics}

Panel A of Table 1 reports the descriptive statistics for all sample companies. The number of observations are 137,649 for bid-ask spread (S), 137,519 for price depth (ILLQ), 137,649 for volatility (Sigma) and 137,647 for high-low price variation (HL). Moreover, the volume of day trading (DV) and the percentage of day trading (DVP) consist of 137,653 and 137,519 observations, respectively. The set of control variables includes the following trading variables and company characteristics, namely, turnover rate, positive return, negative return, debt rate, firm size and the price level of the stock market.

Our sample is across different industries; therefore, we classify our sample into three categories, namely, the financial sector, electronics sector and other sectors. Panels B-D present the corresponding results for each industry type. As shown in Panel B of Table 1, the mean of S, Sigma and HL in the financial industry are 4.132, 1.360 and 1.642, respectively, which are higher than the whole sample. Meanwhile, day trading in the financial sector is higher in share volume but smaller in percentage volume than that of the whole sample. Descriptive statistics for the electronics industry (Panel C) and other industries (Panel D) are relatively similar to Panel A. 


\begin{tabular}{|c|c|c|c|c|c|c|c|}
\hline Variables & Mean & Std & Min & Median & Max & $N$ & Day trading \\
\hline \multicolumn{8}{|c|}{ Panel A: All companies } \\
\hline$S$ & 6.132 & 8.433 & 0.000 & 2.807 & 96.149 & 137,649 & \multirow{12}{*}{197} \\
\hline Sigma & 2.241 & 9.566 & 0.000 & 1.293 & 726.221 & 137,649 & \\
\hline ILLQ & -7.442 & 2.253 & -11.422 & -7.959 & 0.000 & 137,519 & \\
\hline$H L$ & 2.762 & 1.869 & 0.000 & 2.255 & 21.466 & 137,647 & \\
\hline$D V$ & 1.583 & 1.030 & 0.000 & 1.708 & 5.217 & 137,653 & \\
\hline$D V P$ & 0.064 & 0.070 & 0.000 & 0.043 & 0.751 & 137,519 & \\
\hline Turnover & 0.007 & 0.012 & 0.000 & 0.003 & 0.279 & 137,653 & \\
\hline Retp & 0.782 & 1.497 & 0.000 & 0.000 & 10.000 & 137,653 & \\
\hline Retn & -0.785 & 1.396 & -10.000 & 0.000 & 0.000 & 137,653 & \\
\hline$D R$ & 0.447 & 0.194 & 0.000 & 0.440 & 0.977 & 137,653 & \\
\hline MI & 3.999 & 0.022 & 3.930 & 3.998 & 4.048 & 137,653 & \\
\hline Size & 4.246 & 0.587 & 0.000 & 4.189 & 6.699 & 137,653 & \\
\hline \multicolumn{8}{|c|}{ Panel B: Financial industry } \\
\hline$S$ & 4.132 & 5.285 & 0.000 & 2.274 & 58.898 & 8,811 & \\
\hline Sigma & 1.360 & 7.769 & 0.000 & 0.753 & 474.663 & 8,811 & \\
\hline ILLQ & -7.862 & 2.926 & -11.244 & -8.918 & 0.000 & 8,810 & \\
\hline$H L$ & 1.642 & 1.075 & 0.000 & 1.385 & 11.786 & 8,810 & \\
\hline$D V$ & 1.851 & 1.023 & 0.000 & 2.068 & 4.459 & 8,814 & \\
\hline$D V P$ & 0.023 & 0.025 & 0.000 & 0.016 & 0.320 & 8,810 & \\
\hline \multicolumn{8}{|c|}{ Panel C: Electronics industry } \\
\hline$S$ & 6.518 & 8.976 & 0.000 & 2.753 & 96.149 & 77,696 & \\
\hline Sigma & 2.471 & 10.385 & 0.000 & 1.454 & 726.221 & 77,696 & \\
\hline$I L L Q$ & -7.485 & 2.175 & -11.422 & 0.000 & -7.972 & 77,573 & \\
\hline$H L$ & 3.003 & 1.957 & 0.000 & 2.484 & 21.466 & 77,696 & \\
\hline$D V$ & 1.685 & 1.055 & 0.000 & 1.839 & 5.217 & 77,696 & \\
\hline$D V P$ & 0.074 & 0.074 & 0.000 & 0.054 & 0.737 & 77,573 & \\
\hline \multicolumn{8}{|c|}{ Panel D: Other industries } \\
\hline$S$ & 5.915 & 7.987 & 0.000 & 3.028 & 90.410 & 51,142 & \\
\hline Sigma & 2.048 & 8.501 & 0.000 & 1.193 & 562.437 & 51,142 & \\
\hline ILLQ & -7.316 & 2.221 & -10.306 & -7.861 & 0.000 & 51,136 & \\
\hline$H L$ & 2.594 & 1.749 & 0.000 & 2.116 & 18.813 & 51,141 & \\
\hline$D V$ & 1.395 & 0.950 & 0.000 & 1.491 & 4.361 & 51,143 & \\
\hline$D V P$ & 0.057 & 0.066 & 0.000 & 0.035 & 0.751 & 51,136 & \\
\hline \multicolumn{8}{|c|}{$\begin{array}{l}\text { Note: The sample period is from June 1, } 2015 \text { to October } 31,2016 \text {, including } 349 \text { trading days for } 396 \\
\text { individual stocks. S, bid-ask spread; Sigma, stock volatility; ILLQ, price depth; HL, difference between the } \\
\text { highest and lowest price within a trading day; } D V \text {, share volume of day trading; } D V P \text {, percentage volume of } \\
\text { day trading percentage; Turnover, daily trading turnover; Retp, positive component of daily stock return; } \\
\text { Retn, negative component of daily stock return; } D R \text {, ratio of total debt over the total asset; Size, logarithmic } \\
\text { market value of a stock; } M I \text {, logarithmic price index (Formosa Stock Index) to measure the level of Taiwan } \\
\text { stock market. Panels A-D present the results for the whole sample, companies in the financial industry, } \\
\text { companies in the electronics industry and companies in other industries, respectively }\end{array}$} \\
\hline
\end{tabular}

\subsection{Correlation analysis}

Table 2 shows the correlation among variables. As reported, day trading ( $D V$ and $D V P)$ is positively related to $S$, Sigma and $H L$, but negatively related to $I L L Q$. The results imply that the influences of day trading vary among different aspects of market quality. Table 2 also shows that the correlation between each variable is low, suggesting that the collinearity problem would not alter the empirical results. 
JDQS
28,4

198

Table 2.

Correlation coefficient matrix

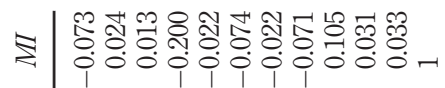

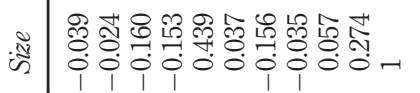

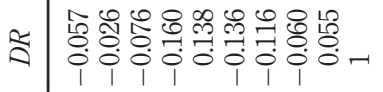

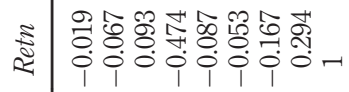

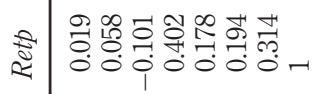

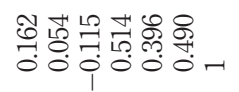

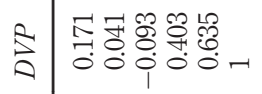

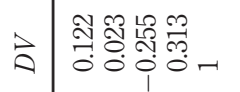

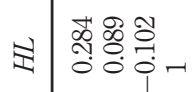

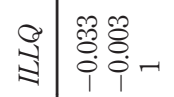

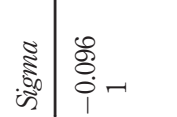

s

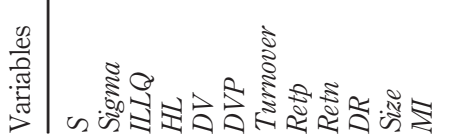




\subsection{Empirical results}

We begin the analysis with the influence on stock liquidity. The analysis results using bidask spread and price depth as dependent variables are presented in Tables 3 and 4, respectively. Control variables are given in the regression model step by step to test if the influence of day trading is stable under various settings.

As can be seen, day trading is positively related to the bid-ask spread, no matter how we control other variables in each setting. Bid-ask spread presents the cost of the transaction; therefore, this finding suggests that day trading is harmful to market quality.

In Table 4, however, we find that day trading is negatively related to ILLQ irrespective of the different settings for control variables. The smaller ILLQ, the greater is the price depth. Day trading, therefore, tends to increase stock liquidity as shown in Table 4, which is in contrast to that in Table 3. The findings above imply that the impact of day trading on stock liquidity is disparate in various aspects. Day trading may increase transaction costs but simultaneously enhance the market absorption of the price impact from trading. This argument is consistent with the literature findings that trading has diverse influences on the market.

For the impact of day trading on stock volatility, the results by Sigma are presented in Table 5. The empirical findings show that day trading is positively related to stock volatility regardless of different settings for control variables, suggesting that day trading will increase stock volatility.

We also replace Sigma by $H L$ and replicate the regression analysis in Table 5; the results are qualitatively similar to the ones reported in Table 5.

Furthermore, we replace the share volume of day trading by the percentage volume and reexamine the results from Tables 3 to 5 . Again, we obtain results similar to the existing

\begin{tabular}{lcccr} 
& \multicolumn{4}{c}{ Dependent: $S$} \\
Regression models & $(1)$ & $(2)$ & $(3)$ & $(4)$ \\
\hline Intercept & $114.720^{* * * *}(0.000)$ & $119.934^{* * * *}(0.000)$ & $121.829^{* * * *}(0.000)$ & $120.738^{* * * *}(0.000)$ \\
$D V$ & $1.623^{* * * *}(0.000)$ & $1.176^{* * * *}(0.000)$ & $1.592^{* * * *}(0.000)$ & $1.244^{* * * *}(0.000)$ \\
Turnover & - & $76.835^{* * * *}(0.000)$ & - & $90.520^{* * * *}(0.000)$ \\
Retp & $-0.155^{* * * *}(0.000)$ & - & - & $-0.330^{* * * *(0.000)}$ \\
Retn & $-0.246^{* * * *}(0.000)$ & - & - & $-0.121^{* * * *}(0.000)$ \\
$D R$ & $0.036(0.906)$ & $0.104(0.730)$ & $0.080(0.792)$ & $0.047(0.876)$ \\
Size & $2.854^{* * * *}(0.000)$ & $1.215^{* * * *}(0.001)$ & $2.507^{* * * *}(0.000)$ & $1.297 * *(0.000)$ \\
$M I$ & $-30.930^{* * *}(0.000)$ & $-30.451^{* * * *}(0.000)$ & $-32.328^{* * * *}(0.000)$ & $-30.729^{* * * *}(0.000)$ \\
Weekday_Effect & Yes & Yes & Yes & Yes \\
Month_Effect & Yes & Yes & Yes & Yes \\
Adjusted- $R^{2}$ & 0.056 & 0.058 & 0.053 & 0.062 \\
$N$ & 137,649 & 137,649 & 137,649 & 137,649
\end{tabular}

Note: The following is the regression model for the analysis of the day trading impact on the bid-ask spread:

$$
S_{t, i}=\alpha+\beta_{1} D V_{t, i}+\beta_{2} \text { Turnover }_{t, i}+\beta_{3} \operatorname{Retp}_{t, i}+\beta_{4} \operatorname{Retn}_{t, i}+\beta_{5} D R_{i}+\beta_{6} \text { Size }_{i}+\beta_{7} M_{t}+\varepsilon_{t}
$$

where $S_{t, i}$ is the bid-ask spread, $D V_{t, i}$ is the day trading volume, Turnover $_{t, i}$ is the turnover rate and $\operatorname{Retp}_{t, i}$ and $\operatorname{Retn}_{t, i}$ are the positive and negative returns. All aforementioned variables are for stock $i$ at day $t$. Moreover, $D R_{t}$ is the debt ratio for stock $i$, Size $e_{t}$ is the logarithm market value for stock $i$ and $M I_{t}$ is the stock market index at day t. The analysis is conducted using panel regression. The $p$-values are in parentheses. $* * *$ denotes the significance at the $1 \%$
Day trading activity

199

$-$




\section{JDQS 28,4}

Regression models

(1)

Dependent: $I L L Q$

\begin{tabular}{|c|c|c|c|c|c|}
\hline \multirow{12}{*}{200} & Intercept & $1.551(0.273)$ & $-9.585^{* * * *}(0.000)$ & $-9.888^{* * * *}(0.000)$ & $1.544(0.275)$ \\
\hline & $D V$ & $-0.241^{* * *}(0.000)$ & $-0.300^{* * * *}(0.000)$ & $-0.368 * * *(0.000)$ & $-0.240 * * *(0.000)$ \\
\hline & Turnover & - & $-12.631^{* * * *}(0.000)$ & - & $-0.099(0.899)$ \\
\hline & Retp & $-0.181^{* * * *}(0.000)$ & - & - & $-0.181 * * *(0.000)$ \\
\hline & Retn & $0.202^{* * *}(0.000)$ & - & - & $0.202^{* * *}(0.000)$ \\
\hline & $D R$ & $0.165 * *(0.036)$ & $0.173^{* * *}(0.029)$ & $0.176^{* *}(0.026)$ & $0.165 * *(0.036)$ \\
\hline & Size & $-0.824 * * *(0.000)$ & $-0.485^{* * *}(0.000)$ & $-0.704 * * *(0.000)$ & $-0.822 * * *(0.000)$ \\
\hline & $M I$ & $-1.215^{* * *}(0.001)$ & $1.174 * * * *(0.001)$ & $1.497 * * *(0.000)$ & $-1.215^{* * *}(0.001)$ \\
\hline & Week_Effect & Yes & Yes & Yes & Yes \\
\hline & Month_Effect & Yes & Yes & Yes & Yes \\
\hline & Adjusted- $R^{2}$ & 0.114 & 0.098 & 0.096 & 0.114 \\
\hline & $N$ & 137,519 & 137,519 & 137,519 & 137,519 \\
\hline
\end{tabular}

Note: The following is the regression model for the analysis of the day trading impact on price depth:

$I L L Q_{t, i}=\alpha+\beta_{1} D V_{t, i}+\beta_{2}$ Turnover $_{t, i}+\beta_{3} \operatorname{Retp}_{t, i}+\beta_{4} \operatorname{Retn}_{t, i}+\beta_{5}$ DR $_{i}+\beta_{6}$ Size $_{i}+\beta_{7} M_{t}+\varepsilon_{t}$

\section{Table 4.}

The impact of day trading on price depth where $I L L Q_{t, i}$ is the illiquidity ratio presenting price depth, $D V_{t, i}$ is day trading volume, Turnover $_{t, i}$ is the turnover rate and $\operatorname{Retp}_{t, i}$ and $\operatorname{Retn}_{t, i}$ are positive and negative return, respectively. The aforementioned variables are for stock $i$ at day t. Moreover, $D R_{t}$ is the debt ratio for stock $i$, Size $e_{t}$ is the logarithm market value for stock $i$ and $M I_{t}$ is the stock market index at day t. The analysis is conducted using panel regression. The $p$-values are in parentheses. $* *$ and $* * *$ denote the significance at the $5 \%$ and $1 \%$, respectively
Table 5.

The impact of day trading on stock volatility
Dependent: Sigma

Regression models

(1)

(2)

(3)

(4)

\begin{tabular}{lccrr}
\hline Intercept & $-55.353^{* * *}(0.000)$ & $-23.422^{* * * *}(0.000)$ & $-22.483^{* * * *}(0.000)$ & $-55.128^{* * *}(0.000)$ \\
DV & $0.176^{* * *}(0.000)$ & $0.327^{* * * *}(0.000)$ & $0.533^{* * *}(0.000)$ & $0.162^{* * *}(0.000)$ \\
Turnover & - & $38.076^{* * *}(0.000)$ & - & $3.398(0.324)$ \\
Retp & $0.499^{* * *}(0.000)$ & - & - & $0.492^{* * *}(0.000)$ \\
Retn & $-0.591^{* * * *}(0.000)$ & - & - & $-0.587^{* * *}(0.000)$ \\
DR & $-0.428(0.219)$ & $-0.445(0.203)$ & $-0.457(0.191)$ & $-0.428(0.219)$ \\
Size & $-2.271^{* * *}(0.000)$ & $-3.256^{* * * *}(0.000)$ & $-2.616^{* * *}(0.000)$ & $-2.329 * * *(0.000)$ \\
MI & $16.374^{* * *}(0.000)$ & $9.510^{* * *}(0.000)$ & $8.579 * * *(0.000)$ & $16.381^{* * *}(0.000)$ \\
Weekday_Effect & Yes & Yes & Yes & Yes \\
Month_Effect & Yes & Yes & Yes & Yes \\
Adjusted- $R^{2}$ & 0.029 & 0.022 & 0.021 & 0.029 \\
$N$ & 137,649 & 137,649 & 137,649 & 137,649
\end{tabular}

Note: The regression model for the analysis of day trading impact on stock volatility is as follows:

$$
\operatorname{Sigma}_{t, i}=\alpha+\beta_{1} D V_{t, i}+\beta_{2} \text { Turnover }_{t, i}+\beta_{3} \text { Retp }_{t, i}+\beta_{4} \operatorname{Retn}_{t, i}+\beta_{5} D R_{i}+\beta_{6} \text { Size }_{i}+\beta_{7} M I_{t}+\varepsilon_{t}
$$

where Sigma $a_{t, i}$ is the stock volatility, $D V_{t, i}$ is the day trading volume, Turnover ${ }_{t, i}$ is the turnover rate and $\operatorname{Retp}_{t, i}$ and $\operatorname{Retn}_{t, i}$ are positive and negative returns, respectively. The aforementioned variables are for stock $i$ at day t. Moreover, $D R_{t}$ is the debt ratio for stock $i$, Size $e_{t}$ is the logarithm market value for stock $i$ and $M I_{t}$ is the stock market index at day t. The analysis is conducted using panel regression. The $p$-values are in parentheses. ***denotes the significance at the $1 \%$ 
findings: day trading activities tend to widen the bid-ask spread, increase price depth and cause higher stock volatility [6].

To address possible differences between industries, we also perform the same analysis by industry subsample with similar classification in Table 1 . The empirical results show that the influence of day trading on the bid-ask spread and stock volatility in each industry category is similar to the full sample. The impact of day trading on price depth is slightly different across industries. The influence of day trading on price depth is not significant in the financial industry compared with that in the non-financial sectors, implying that day trading does not positively impact financial companies.

In brief, irrespective of using the dollar volume or the dollar volume percentage of day trading (DV or DVP) or the methods of augmenting control variables, we find similar results about the influence of day trading in most of our sample companies. However, as motioned earlier, the possible endogeneity problem among day trading and dependent variables is still a concern: the behavior of day traders might also be driven by wider bid-ask spread, greater price depth and higher volatility. To alleviate such a problem, alternately, we use two-stage regression to deal with the endogeneity problem. We find that day trading activity in day $t-1$ is closely related to that in day $t$ but weakly related to market quality variables in day $t$. Hence, we choose the percentage of day trading in the previous day as an instrument variable in the first stage of the regression.

Similar to Tables $3-5$, in Tables $6-8$, we show the results of two-stage regression for bidask spread, price depth and stock volatility (Sigma), respectively [7]. The results presented in Tables 6-8 are qualitatively similar to those in Tables 3-5. Again, we replace the share volume of day trading by the percentage volume and redo the analysis from Tables $6-8$;

Regression models

(1)

(2)

Dependent: $S$

\begin{tabular}{lcccr}
\hline Intercept & $119.076^{* * *}(0.000)$ & $124.036^{* * *}(0.000)$ & $126.044^{* * * *}(0.000)$ & $134.971^{* * * *}(0.000)$ \\
DV & $1.615^{* * * *}(0.000)$ & $1.170^{* * * *}(0.000)$ & $1.579^{* * * *}(0.000)$ & $1.239^{* * * *}(0.000)$ \\
Turnover & - & $75.896^{* * * *}(0.000)$ & - & $89.771^{* * * *}(0.000)$ \\
Retp & $-0.161^{* * *}(0.000)$ & - & - & $-0.334^{* * * *}(0.000)$ \\
Retn & $-0.243^{* * *}(0.000)$ & - & - & $-0.117 * * * 0.000)$ \\
DR & $0.044(0.885)$ & $0.113(0.709)$ & $0.089(0.768)$ & $0.054(0.858)$ \\
Size & $2.857^{* * * *}(0.000)$ & $1.224^{* * * *}(0.001)$ & $2.503^{* * * *}(0.000)$ & $1.308^{* * * *}(0.000)$ \\
MI & $-32.015^{* * * *}(0.000)$ & $-31.480^{* * * *}(0.000)$ & $-33.372^{* * * *}(0.000)$ & $-31.793^{* * *}(0.000)$ \\
Weekday_Effect & Yes & Yes & Yes & Yes \\
Month_Effect & Yes & Yes & Yes & Yes \\
Adjusted- $R^{2}$ & 0.056 & 0.058 & 0.053 & 0.062 \\
$N$ & 137,253 & 137,253 & 137,253 & 137,253
\end{tabular}

Note: The following is the regression model for the analysis of day trading impact on the bid-ask spread using two-stage regression:

$$
S_{t, i}=\alpha+\beta_{1} D V_{t, i}+\beta_{2} \text { Turnover }_{t, i}+\beta_{3} \text { Retp }_{t, i}+\beta_{4} \operatorname{Retn}_{t, i}+\beta_{5} D R_{i}+\beta_{6} \text { Size }_{i}+\beta_{7} M I_{t}+\varepsilon_{t}
$$

where $S_{t, i}$ is bid-ask spread, $D V_{t, i}$ is the day trading volume, Turnover $_{t, i}$ is the turnover rate and $\operatorname{Ret}_{t, i}$ and $\operatorname{Retn}_{t, i}$ are positive and negative returns, respectively. All aforementioned variables are for stock $i$ at day $t$. Moreover, $D R_{t}$ is the debt ratio for stock $i$, Size $_{t}$ is the logarithm market value for stock $i$ and $M I_{t}$ is the stock market index at day $t$. This table reports the results of the second stage of regression. The $p$-values are in parentheses. $* * *$ denotes the significance at the $1 \%$
Day trading activity

201

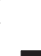




\section{JDQS 28,4}

Regression models

Dependent: ILLQ

\begin{tabular}{|c|c|c|c|c|c|}
\hline \multirow{12}{*}{202} & Intercept & $1.304(0.359)$ & $-9.945^{* * *}(0.000)$ & $-10.271^{* * *}(0.000)$ & $1.297(0.362)$ \\
\hline & $D V$ & $-0.240 * * *(0.000)$ & $-0.299 * * *(0.000)$ & $-0.367 * * *(0.000)$ & $-0.239 * * *(0.000)$ \\
\hline & Turnover & - & $-12.643 * * *(0.000)$ & - & $-0.097(0.901)$ \\
\hline & Retp & $-0.181^{* * *}(0.000)$ & - & - & $-0.181 * * *(0.000)$ \\
\hline & Retn & $0.202^{* * *}(0.000)$ & - & - & $0.202 * * *(0.000)$ \\
\hline & $D R$ & $0.163^{* *}(0.038)$ & $0.172 * *(0.030)$ & $0.175^{* *}(0.027)$ & $0.163 * *(0.038)$ \\
\hline & Size & $-0.830 * * *(0.000)$ & $-0.478 * * *(0.000)$ & $-0.707 * * *(0.000)$ & $-0.828 * * *(0.000)$ \\
\hline & $M I$ & $-1.147^{* * * *}(0.002)$ & $1.267 * * * *(0.001)$ & $1.597 * * *(0.000)$ & $-1.147 * * *(0.002)$ \\
\hline & Week_Effect & Yes & Yes & Yes & Yes \\
\hline & Month_Effect & Yes & Yes & Yes & Yes \\
\hline & Adjusted- $R^{2}$ & 0.114 & 0.098 & 0.096 & 0.114 \\
\hline & $N$ & 137,123 & 137,123 & 137,123 & 137,123 \\
\hline
\end{tabular}

Note: The following is the regression model for the analysis of the impact of day trading on price depth using two-stage regression:

$$
I L L Q_{t, i}=\alpha+\beta_{1} D V_{t, i}+\beta_{2} \text { Turnover }_{t, i}+\beta_{3} \operatorname{Retp}_{t, i}+\beta_{4} \operatorname{Retn}_{t, i}+\beta_{5} D R_{i}+\beta_{6} \text { Size }_{i}+\beta_{7} M I_{t}+\varepsilon_{t}
$$

Table 7 .

The impact of day trading on price depth (two-stage regression) where $I L L Q_{t, i}$ is the illiquidity ratio presenting price depth, $D V_{t, i}$ is the day trading volume, Turnover $_{t, i}$ is the turnover rate and $\operatorname{Ret}_{t, i}$ and $\operatorname{Retn}_{t, i}$ are positive and negative returns. All aforementioned variables are for stock $i$ at day t. Moreover, $D R_{t}$ is the debt ratio for stock $i$, Size $e_{t}$ is the logarithm market value for stock $i$ and $M I_{t}$ is the stock market index at day t. This table reports the results of the second stage. The $p$-values are in parentheses. $* *$ and $* * *$ denote the significance at the $5 \%$ and $1 \%$, respectively

\section{Table 8.}

The impact of day trading on stock volatility (two-stage regression)
Regression models

(1) Dependent: Sigma

\begin{tabular}{lccrr}
\hline Intercept & $-58.297^{* * *}(0.000)$ & $-25.936^{* * *}(0.000)$ & $-24.926^{* * * *}(0.000)$ & $-58.075^{* * *}(0.000)$ \\
DV & $0.178^{* * *}(0.000)$ & $0.330^{* * *}(0.000)$ & $0.536^{* * *}(0.000)$ & $0.164^{* * *}(0.000)$ \\
Turnover & - & $38.156^{* * *}(0.000)$ & - & $3.379(0.328)$ \\
Retp & $0.500^{* * *}(0.000)$ & - & - & $0.493^{* * *}(0.000)$ \\
Retn & $-0.594^{* * *}(0.000)$ & - & - & $-0.589^{* * *}(0.000)$ \\
DR & $-0.439(0.208)$ & $-0.457(0.192)$ & $-0.469(0.181)$ & $-0.439(0.209)$ \\
Size & $-2.241^{* * *}(0.000)$ & $-3.238^{* * *}(0.000)$ & $-2.595^{* * *}(0.000)$ & $-2.299^{* * *}(0.000)$ \\
$M I$ & $17.076^{* * *}(0.000)$ & $10.117^{* * * *}(0.000)$ & $9.167^{* * *}(0.000)$ & $17.085^{* * *}(0.000)$ \\
Weekday_Effect & Yes & Yes & Yes & Yes \\
Month_Effect & Yes & Yes & Yes & Yes \\
Adjusted- $R^{2}$ & 0.029 & 0.022 & 0.021 & 0.029 \\
$N$ & 137,253 & 137,253 & 137,253 & 137,253
\end{tabular}

Note: The following is the regression model for the analysis of the impact of day trading on stock volatility using two-stage regression:

$$
\operatorname{Sigma}_{t, i}=\alpha+\beta_{1} D V_{t, i}+\beta_{2} \text { Turnover }_{t, i}+\beta_{3} \operatorname{Retp}_{t, i}+\beta_{4} \operatorname{Retn}_{t, i}+\beta_{5} D R_{i}+\beta_{6} \operatorname{Size}_{i}+\beta_{7} M I_{t}+\varepsilon_{t}
$$

where Sigma $a_{t, i}$ is the stock volatility, $D V_{t, i}$ is the day trading volume, Turnover ${ }_{t, i}$ is the turnover rate and $\operatorname{Retp}_{t, i}$ and $\operatorname{Retn}_{t, i}$ are positive and negative returns, respectively. All aforementioned variables are for stock $i$ at day t. Moreover, $D R_{t}$ is the debt ratio for stock $i$, Size $e_{t}$ is the logarithm market value for stock $i$ and $M I_{t}$ is the stock market index at day $t$. This table reports the results of the second stage of the regression analysis. The $p$-values are in parentheses. $* * *$ denotes the significance at the $1 \%$ 
besides, we replace Sigma in Table 8 by $H L$ and reexamine the results. All these alternate tests do not override the present findings of the two-stage regression analysis.

We continue to consider an exogenous shock for day trading to deal with the possible endogeneity. Different from two-stage regression, the exogenous shock can further allow us to observe the impact of a specific change in day trading activities on the stock market directly because reverse causality does not exist. On the TWSE, the further relaxation of day trading policy on June 1, 2015, can be viewed as an exogenous shock to day trading activity. On that day, in addition to the 200 companies initially selected, the TWSE allowed more activity stocks to be eligible for day trading. Apparently, before further relaxation, the newly permitted stocks were prohibited from day trading. Immediately right after the relaxation, the changes in trading variables for the newly permitted stocks should be more purely driven by the changes in day trading. We expect that the shock will only increase the volume of day trading for new stocks; therefore, the changes in any market quality variables should only be seen in these companies. By contrast, for the stocks that were eligible for day trading before June 1, 2015, the changes should be weaker. To minimize any other implicit exogenous disturbance around the same period, we narrow our observation window to five trading days before and after the policy implementation on June 1, 2015. We calculate the average values for $D V, D V P, S, I L L Q$, Sigma and $H L$ for the full sample, each subsample (originally eligible and newly eligible group) in two windows (before and after). The results are presented in Table 9 .

In Table 9, the "full sample" (Panel A) comprises 396 eligible day trading stocks. The "original sample" (Panel B) is consists of 197-day trading stocks that are available for day trading before June 1, 2015. The "new sample" (Panel C) comprises 199 stocks that are newly eligible for day trading after June 1, 2015.

As can be seen, the differences between the pre-relaxation and post-relaxation implementation for all variables are more significant in newly eligible stocks (Panel C). All changes in each variable after the relaxation are statistically significant in Panel $\mathrm{C}$, whereas the same effect cannot be seen in Panel B. Also, the magnitude of the changes in Panel B is smaller than that in Panel C.

Overall, the findings in Table 9 support our expectation: an increase in day trading will increase the bid-ask spread and stock volatility but decrease price impact. This finding is also consistent with those in previous tables.

\section{Conclusion}

In this paper, we investigate the influence of day trading on market quality through a direct measure of day trading activity of nearly 400 individual stocks on the TWSE. Market quality is proxied by various stock liquidity and volatility variables. Our empirical findings show that although the eligibility of day trading increases the trading volume on the TWSE, it is not entirely beneficial to market quality. Day trading tends to increase the bid-ask spread and stock volatility, and more day trading activities raise price depth for stocks. Our findings survive various empirical settings, including alternate day trading variables, volatility proxy and different control variables. To alleviate the concern of the endogeneity problem, we propose two-state regression to reexamine our results; moreover, we consider an exogenous shock in day trading policy to observe the subsequent changes in stock liquidity and volatility variables. All these analyzes suggest consistent results.

Through our findings, we believe that the removal of day trading restrictions on the Taiwan stock market boosts trading volume. However, we also show that frequent day trading is not entirely beneficial for the market; in particular, the increased bid-ask 


\begin{tabular}{|c|c|c|c|c|c|}
\hline \multirow{2}{*}{$\begin{array}{l}\text { JDQS } \\
28,4\end{array}$} & Variables & Before & After & Difference & $N$ \\
\hline & $\begin{array}{l}\text { Panel A: Full sample } \\
\text { DV } \\
\text { DVP } \\
\text { S } \\
\text { ILLQ } \\
\text { HL } \\
\text { Sigma }\end{array}$ & $\begin{array}{r}0.970 \\
0.029 \\
0.006 \\
-7.597 \\
2.458 \\
0.016\end{array}$ & $\begin{array}{r}1.818 \\
0.059 \\
0.007 \\
-7.714 \\
3.684 \\
0.025\end{array}$ & $\begin{array}{c}0.848^{* * * *} \\
0.030^{* * * *} \\
0.001^{* * * *} \\
-0.117^{*} \\
1.226^{* * * *} \\
0.009^{* * *}\end{array}$ & $\begin{array}{l}396 \\
396 \\
396 \\
396 \\
396 \\
396\end{array}$ \\
\hline \multirow{2}{*}{204} & $\begin{array}{l}\text { Panel B: Original sam } \\
D V \\
D V P \\
\text { S } \\
\text { ILLQ } \\
\text { HL } \\
\text { Sigma }\end{array}$ & $\begin{array}{r}\text { sible befo } \\
1.950 \\
0.059 \\
0.006 \\
-7.803 \\
2.227 \\
0.014\end{array}$ & $\begin{array}{r}1.994 \\
0.060 \\
0.006 \\
-7.886 \\
3.012 \\
0.021\end{array}$ & $\begin{array}{l}0.044^{\text {** }} \\
0.001^{\text {**** }} \\
0.001^{\text {* }} \\
-0.083^{* * * *} \\
0.785^{* * * * *} \\
0.006^{\text {*** }}\end{array}$ & $\begin{array}{l}197 \\
197 \\
197 \\
197 \\
197 \\
197\end{array}$ \\
\hline & $\begin{array}{l}\text { Panel C: New sample } \\
\text { DV } \\
D V P \\
\text { S } \\
\text { ILLQ } \\
\text { HL } \\
\text { Sigma }\end{array}$ & $\begin{array}{r}\text { after Jur } \\
0.000 \\
0.000 \\
0.006 \\
-7.392 \\
2.687 \\
0.019\end{array}$ & $\begin{array}{r}1.643 \\
0.058 \\
0.008 \\
-7.543 \\
4.349 \\
0.030\end{array}$ & $\begin{array}{c}1.643^{* * *} \\
0.058^{* * *} \\
0.002^{* * * *} \\
-0.152^{*} \\
1.662^{* * *} \\
0.012^{* * *}\end{array}$ & $\begin{array}{l}199 \\
199 \\
199 \\
199 \\
199 \\
199\end{array}$ \\
\hline
\end{tabular}

Note: This table presents the average values for $D V, D V P, S$, ILLQ, Sigma and $H L$ for the full sample, each subsample (originally eligible and newly eligible group) in two windows (before and after). On the TWSE, a further relaxation of day trading policy on June 1, 2015, can be viewed as an exogenous shock to day trading activity. On that day, in addition to the initially selected companies, the TWSE allowed more stocks to be eligible for day trading. The "Full Sample" (Panel A) comprises 396 eligible day trading stocks. The "Original Sample" (Panel B) is consists of 197 day trading stocks that are available for day trading before

Table 9.

The exogenous shock of day-trading
June 1, 2015. The "New Sample" (Panel C) comprises 199 stocks that are newly eligible for day trading after June 1,2015 . Differences are examined by $T$-test. *, ** and *** denote significance at the 10,5 and $1 \%$, respectively

spread and stock volatility would directly harm the trading performance for investors. Existence literature seldom discusses the influence of day trading on market quality because of the lack of direct day trading proxy. This paper contributes to the existing literature in that it investigates the impact of day trading on market quality through direct day trading variables and measures market quality in several aspects. For practical implication, we argue that market regulators should not only stimulate the market to grow but also consider the influence of day trading on the quality of executing transactions. Besides, retail traders should be more aware of the negative impacts of day trading. Although day trading minimizes the delivery costs for stock transactions and could be more attractive for retail traders who are generally cashstrapped, retail traders are also unavoidably more vulnerable to the higher trading risk caused by day trading.

For the unexplored issues in this study, we suggest that further research should consider more measures for stock liquidity and volatility. Furthermore, the influence of a transaction tax cut for day trading $(0.3 \%$ to $0.15 \%)$ on April 28,2017 , will be a follow-up study worthy for further exploring. 


\section{Notes}

1. The TWSE was established in 1961 and began operating as a stock exchange market on February 9, 1962. In terms of the market capitalization, the TWSE is commonly ranked as top 10 and 20 stock exchange in Asia and the world, respectively.

2. News report from Anna Kitanaka, "The New Rise of Day Trading in Japan," Bloomberg Business, July 12, 2013.

3. The TWSE only allowed "buy first and sell out later" day trading from January 1, 2014, for 150 selected stocks. After six months, the exchange further permitted "sell first and buy back later" day trading. From June 1, 2015, the number of stocks permitted increased from 150 to nearly 400.

4. In addition, the lower illiquidity ratio may partly come from the dollar volume used in the denominator of the ratio. Day traders' trading volume may be greater than other traders' trading volume, which leads to a low illiquidity ratio. We thank an anonymous reviewer for suggesting this alternate explanation.

5. Before the policy, only the 150 selected stocks are permitted to engage in day trading. After the policy, the TWSE enabled all stocks that were underlying assets of equity warrants to be allowed in day trading. This further relaxation increases the number of day trading stocks to nearly 400 .

6. For brevity, we did not report similar results using the alternate variables.

7. We report the results of the outcome regression (the second-stage regression) in Tables 6-8.

\section{References}

Amihud, Y. (2002), "Illiquidity and stock returns: cross-section and time-series effects", Journal of Financial Markets, Vol. 5 No. 1, pp. 31-56.

Barber, B.M. and Odean, T. (2001), "The internet and the investor", Journal of Economic Perspectives, Vol. 15 No. 1, pp. 41-54.

Battalio, R.H., Hatch, B. and Jennings, R. (1997), "SOES trading and stock volatility", The Journal of Financial and Quantitative Analysis, Vol. 32 No. 2, pp. 225-238.

Black, F. (1986), "Noise”, Journal of Finance, Vol. 41, pp. 529-543.

Bloomfield, R., O'Hara, M. and Saar, G. (2009), "How noise trading affects markets: an experimental analysis", Review of Financial Studies, Vol. 22 No. 6, pp. 2275-2302.

Chou, R.K., Wang, G.H. and Wang, Y.Y. (2015), "The impacts of individual day trading strategies on market liquidity and volatility: evidence from the Taiwan index futures market", Journal of Futures Markets, Vol. 35 No. 5, pp. 399-425.

Chung, J.M., Choe, H. and Kho, B.C. (2009), "The impact of day-trading on volatility and liquidity”, AsiaPacific Journal of Financial Studies, Vol. 38 No. 2, pp. 237-275.

Corwin, S.A. and Schultz, P. (2012), "A simple way to estimate bid-ask spreads from daily high and low prices", The Journal of Finance, Vol. 67 No. 2, pp. 719-760.

Harris, J.H. and Schultz, P.H. (1998), "The trading profits of SOES bandits", Journal of Financial Economics, Vol. 50 No. 1, pp. 39-62.

Hsieh, T.Y., Fu, Y.F. and Ma, S.Y. (2020), "Impacts of day trading on the intraday pattern of market quality", International Journal of Services Technology and Management, Vol. 26 No. 1, pp. 20-37.

Koski, J.L., Rice, E.M. and Tarhouni, A. (2008), "Day trading and volatility: evidence from message board postings in 2002 vs. 1999", Working paper, University of Washington.

Kyrolainen, P. (2008), "Day trading and stock price volatility", Journal of Economics and Finance, Vol. 32, pp. 75-89.

Malkiel, B.G. (1999), “Day trading, and its dangers”, Wall Street Journal, p. A22, August 3. 


\section{Further reading}

Bloomfield, R., O'Hara, M. and Saar, G. (2005), "The 'make or take' decision in an electronic market: evidence on the evolution of liquidity", Journal of Financial Economics, Vol. 75 No. 1, pp. 165-199.

\section{Appendix 1. The approach of Corwin and Schultz (2012)}

We follow the method of Corwin and Schultz (2012) in estimating the bid-ask spread and volatility index. In this study, the highest and the lowest prices in two consecutive days are used to determine the bid-ask spread and volatility index through Models 1 and 2.

Model 1:

$$
\mathrm{S}=2\left(e^{\alpha}-1\right) /\left(1+e^{\alpha}\right)
$$

Model 2:

$$
\operatorname{Sigma}=\sqrt{k \beta / 2}-\sqrt{k} \alpha
$$

As:

$$
\begin{gathered}
\alpha=(\sqrt{2 \beta}-\sqrt{\beta}) /(3-2 \sqrt{2})-\sqrt{\gamma /(3-2 \sqrt{2})} \\
\beta=\sum_{j=0}^{1}\left[\ln \left(H_{t+j}^{O} / L_{t+j}^{O}\right)\right]^{2} \\
\gamma=\left[\ln \left(H_{t, t+1}^{O} / L_{t, t+1}^{O}\right)\right]^{2} \\
\mathrm{k}=1 /(4 \ln 2)
\end{gathered}
$$

$$
H_{t}^{O}\left(L_{t}^{O}\right)=\text { the highest (lowest) price at day } t
$$

$H_{t, t+1}^{O}\left(L_{t, t+1}^{O}\right)=$ the highest (lowest) price between day $t$ and day $t+1$

\section{Appendix 2. Formosa stock index}

The following is the calculation method of the Formosa Stock Index:

$$
\text { Index }=\frac{\text { Market Value }}{\text { Divisor }} \times \text { Base Value }
$$

where:

Market Value $=$ market value of TAIEX + market value of GTEX;

Base Value $=10,000$; and 
Base Date $=$ December 31, 2013.

Meanwhile, the divisor calculation of Formosa Stock Index is as follows (the method also applies to the divisor calculation of total return index):

$$
A I I D_{t+1}=\left[\frac{\left(\frac{T W S E D_{t+1}}{\operatorname{TWSED}_{t}}\right) T W S E M V_{t}+\left(\frac{\operatorname{GTSMD}_{t+1}}{G T S M D_{t}}\right) \operatorname{GTSMMV}_{t}}{\operatorname{TWSEMV}_{t}+\operatorname{GTSMMV}_{t}}\right] A I I D_{t}
$$

where:

AIID = Divisor of Formosa Stock Index;

TWSEMV = Total market value of TAIEX constituents;

GTSMMV = Total market value of GTEX constituents;

TWSED = Divisor of TAIEX; and

GTSMD = Divisor of GTEX.

\section{Corresponding author}

Pei-Shih Weng can be contacted at: psweng@g-mail.nsysu.edu.tw

For instructions on how to order reprints of this article, please visit our website: www.emeraldgrouppublishing.com/licensing/reprints.htm Or contact us for further details: permissions@emeraldinsight.com 